\title{
Surface properties and depth analysis of polyethylene/ polydimethylsiloxane composite prepared by using supercritical carbon dioxide
}

\author{
Rui Zhu ${ }^{1}$, Toru Hoshi ${ }^{2,3}$, Daisuke Sasaki ${ }^{4}$, Ryota Usui ${ }^{1}$, Toshiki Hagiwara ${ }^{2}$, Shoichiro Yano ${ }^{2}$ \\ and Takashi Sawaguchi ${ }^{2,5}$
}

Blends of polyethylene (PE) and polydimethylsiloxane (PDMS) are usually immiscible and have phase-separated morphology. In this study, the polymer composite comprising PE and PDMS with a hydrophobic surface was developed. This composite was obtained by a synthetic method using supercritical carbon dioxide. Results of X-ray photoelectron spectroscopy and attenuated total reflection Fourier-transform infrared spectroscopy indicated that PDMS was located on the surface of the PE substrate. Scanning electron microscope-energy-dispersive X-ray (SEM-EDX) measurement provided the depth information indicating that PDMS existed in the PE substrate. Water contact angle measurement revealed that the hydrophobicity of PE had been improved from 94 to $105^{\circ}$ by incorporating PDMS.

Polymer Journal (2010) 42, 562-566; doi:10.1038/pj.2010.46; published online 2 June 2010

Keywords: hydrophobicity; PDMS; PE; polymer composite; SEM-EDX; supercritical carbon dioxide

\section{INTRODUCTION}

Blending of semicrystalline or crystalline polymers with amorphous polymers has become a popular practice in recent years since the blending concept commenced years back by blending natural rubber with gutta-percha in 1928 and acrylonitrile butadiene rubber with polyvinyl chloride in $1942 .{ }^{1}$ This has led to the development of a broad area of polymer composites and alloys technology in the field of polymer science and engineering. Conventional processing equipments (for example, internal mixers and extruders) are being used for preparing composites and thermoplastic elastomers and also for processing and fabrication of a wide variety of products from these composites. Quite often, these composites may lead to the development of novel polymeric materials with specific end-use properties because of this synergistic combination. Thus, newer application areas and design flexibility have made this composite technique a very popular method for the development of new materials.

Polyethylene (PE) is considered to be the most important class of thermoplastics among all polymers known thus far because of its low cost, good processability and wide range of technical properties. Therefore, it is the most widely used polymer. However, PE has a few disadvantages such as low surface energy, lack of chemical functionalities, difficulty in dyeing and poor compatibility with synthetic polar polymers. Moreover, when a polymer composite of
PE and other polymers is prepared, phase separation occurs, and a macro domain structure is formed because of the crystal growth of $\mathrm{PE}$ from the melt or soluble state. ${ }^{2}$ Because of the stress concentration of the interface of this macro domain, only poor mechanical characteristics can be expected. It is very difficult to realize an improvement in the surface properties of PE.

A synthetic method for producing a new polymer composite using supercritical carbon dioxide $\left(\mathrm{scCO}_{2}\right)$ has been developed. ${ }^{3}$ Both the monomer and initiator dissolved in $\mathrm{scCO}_{2}$ are impregnated into the polymer substrate and subsequently polymerized. Using this method, we have already succeeded in obtaining a micro-phase-separated polymer composite of PE and poly(vinyl acetate) (PVAc), even though they are incompatible with each other and the polymer composite could not have been obtained using conventional methods. ${ }^{4}$ PVAc is blended with the amorphous region in a crystalline polymer (PE) at a molecular level. Thus, it is expected that the polymer composite prepared using the $\mathrm{scCO}_{2}$ method will have favorable mechanical and surface properties.

Polydimethylsiloxane (PDMS) is an inorganic polymer possessing excellent thermal stability, dielectric properties and excellent flame retardancy. It is also widely known owing to its extremely low glass transition temperature, flexibility and hydrophobic surface properties. ${ }^{5-8}$ These properties of PDMS make it suitable for use in different

${ }^{1}$ Department of Materials and Applied Chemistry, Graduate School of Science and Technology, Nihon University, Tokyo, Japan; ${ }^{2}$ Department of Materials and Applied Chemistry, College of Science and Technology, Nihon University, Tokyo, Japan; ${ }^{3}$ Center for Creative Materials Research, Research Institute of Science and Technology, College of Science and Technology, Nihon University, Tokyo, Japan; ${ }^{4}$ Research and Development Division, San-ei Kogyo Corporation, Saitama, Japan and ${ }^{5}$ Research Institute of Science and Technology, College of Science and Technology, Nihon University, Tokyo, Japan

Correspondence: Dr T Hoshi, Department of Materials and Applied Chemistry, College of Science and Technology Nihon University, 1-8-14, Kanda-surugadai, Chiyoda-ku, Tokyo 101-8308, Japan.

E-mail: hoshi@chem.cst.nihon-u.ac.jp

Received 1 March 2010; revised 22 April 2010; accepted 23 April 2010; published online 2 June 2010 
<smiles>C[Si]1(C)O[Si](C)(C)O[Si](C)(C)O[Si](C)(C)O1</smiles>
D4

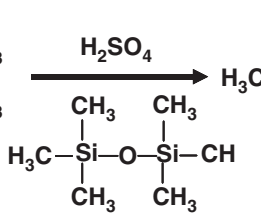

$\mathrm{CH}_{3} \mathrm{CH}_{3}$$$
\text { PDS }
$$

Figure 1 Synthetic scheme for preparation of PDMS.

industries. ${ }^{9-13}$ Several studies have been reported on the phase behavior of PE/PDMS composites. ${ }^{14,15}$ These studies reported that PE and PDMS are immiscible because of the structural dissimilarity, lack of specific interaction and the difference between their surface energies. In this study, we prepared a PE/PDMS polymer composite using $\mathrm{scCO}_{2}$ to obtain $\mathrm{PE}$ with a highly hydrophobic surface. We also studied the relationship between wettability and the structure of PE/ PDMS polymer composite. Thus, the PE/PDMS composite can be applied to some fields, particularly in the biological field. For example, it can replace PDMS and act as a biochip material. Thus, not only is the cost reduced, but also the mechanical properties of a biochip could be expected.

The details of the preparation of PE/PDMS polymer composites are reported here. PDMS was prepared by using octamethylcyclotetrasiloxane (D4). Figure 1 shows synthetic scheme for preparation of PDMS. This reaction belongs to cationic polymerization because of the presence of $\mathrm{H}_{2} \mathrm{SO}_{4} \cdot{ }^{16}$ Adding hexamethyldisiloxane can control the molecular weight of PDMS. The monomer (D4) was impregnated into the $\mathrm{PE}$ substrate by $\mathrm{scCO}_{2}$ and polymerized in situ in $\mathrm{scCO}_{2}$ (Figure 2). Structure characterizations of PE/PDMS polymer composites were performed by X-ray photoelectron spectroscopy (XPS), attenuated total reflection Fourier-transform infrared (ATR-FTIR) spectroscopy and scanning electron microscope-energy-dispersive X-ray (SEM-EDX). Surface hydrophobicity was evaluated by a water static contact angle measurement method.

\section{EXPERIMENTAL PROCEDURE}

\section{Materials}

A linear low-density PE substrate was prepared from a commercial pellet (Mitsui Chemical, Inc, Tokyo, Japan) by hot pressing at $170^{\circ} \mathrm{C}$. The substrate was cut into pieces with dimensions of $20 \times 20 \times 0.5 \mathrm{~mm}^{3}$, extracted with chloroform for $24 \mathrm{~h}$ in a Soxhlet extractor and dried in vacuo at room temperature. D4, hexamethyldisiloxane and sulfuric acid were purchased from Tokyo Chemical Industry Co., Ltd, Tokyo, Japan; Acros Organics, Halluin, France; and Kanto Chemical Co, Tokyo, Japan, respectively. They were used without further purification. $\mathrm{CO}_{2}$ with a purity of $99.5 \%$ was provided by Tomoe Shokai Co, Tokyo, Japan, and used as received.

\section{Preparation of PE/PDMS polymer composite using $\mathrm{scCO}_{2}$}

The apparatus for the preparation of the PE/PDMS polymer composite consisted of a $50 \mathrm{ml}$ stainless steel vessel, magnetic stirrer, constant-temperature air bath (Model SCF-Sro, Jasco Co, Tokyo, Japan), thermocouple and pressure gauge. The pressure gauge comprised a transducer (Model PTX1400, Druck Japan Co, Tokyo, Japan) and an indicator, and it had a precision of $\pm 0.2 \%$ in the pressure range of $0-40 \mathrm{MPa}$. The PE substrate, D4 $(5 \mathrm{~g})$, hexamethyldisiloxane $(0.006 \mathrm{~g})$ as a chain transfer agent and sulfuric acid $(0.013 \mathrm{ml})$ as an initiator were placed in the vessel and sealed. ${ }^{17}$ Air in the vessel was replaced by $\mathrm{CO}_{2}$ at atmospheric pressure. After the system reached thermal equilibrium $\left(35^{\circ} \mathrm{C}\right)$, the vessel was pressurized upto a $\mathrm{CO}_{2}$ pressure of $6 \mathrm{MPa}$ by using a $\mathrm{CO}_{2}$ delivery pump (Model SCF-Get, Jasco Co). The PE substrate was soaked in subcritical $\mathrm{CO}_{2}$ for $1 \mathrm{~h}$. Then the vessel was repressurized upto $6 \mathrm{MPa}$ (to compensate for drop in pressure due to dissolution of the monomer and initiator) and heated to the reaction temperature $\left(80^{\circ} \mathrm{C}\right)$ for a specific time. After the completion of the reaction, the vessel was cooled to $10^{\circ} \mathrm{C}$ in an ice bath and gradually released to ambient pressure. The PE/PDMS polymer composite was dried in vacuo at room temperature after extraction with chloroform for $24 \mathrm{~h}$ at $50{ }^{\circ} \mathrm{C}$ to remove unreacted reagents and the PDMS generated on the surface of the PE/PDMS polymer composite by using a Soxhlet extractor. The mass gain was calculated by the following equation:

$$
\text { Mass gain }(\mathrm{wt} \%)=\left(W_{\mathrm{t}}-W_{0}\right) / W_{0} \times 100
$$

where $W_{0}$ is the initial weight of the PE substrate and $W_{\mathrm{t}}$ is the weight of PE/ PDMS polymer composite sheet after drying.

\section{Surface structure analysis}

To evaluate the chemical structure of the samples and assess the near-surface composition of the PE/PDMS polymer composite, XPS was conducted on an AXIS-HSi (Shimadzu/Kratos, Kyoto, Japan) using Mg K $\alpha$ excitation radiation $(1253.6 \mathrm{eV})$. The takeoff angles of the photoelectron for each atom were fixed at 30 or $90^{\circ}$.

To analyze the functional groups on the surface of the PE/PDMS polymer composite, the ATR-FTIR spectra were measured using an FTIR spectrophotometer (PerkinElmer Spectrum One, PerkinElmer, Waltham, MA, USA) equipped with a universal ATR sampling accessory. All the measurements were performed under identical conditions (number of scans: 8 , resolution: $4 \mathrm{~cm}^{-1}$, 5 points).

\section{Depth direction analysis}

To evaluate the silicon concentration, SEM (Hitachi S-3000N, Hitachi Hightechnology corporation, Tokyo, Japan) and EDX (Hitachi S-3000N, 132-10) analyses of the cross-sections of the PE/PDMS polymer composite were performed. The PE/PDMS polymer composite was cut normally in an ultramicrotome (Leica EM UC6, Leica, Vienna, Austria) at $-160^{\circ} \mathrm{C}$ and then sputter coated with a thin layer of Pt-Pd to improve the electrical conductivity. In all measurements, the acceleration voltage was $15 \mathrm{kV}$.

\section{Water contact angle measurement}

The hydrophilicity of the sample surface was characterized on the basis of water static contact angle measurements. The contact angle with water was measured at room temperature $\left(21^{\circ} \mathrm{C}\right)$ by a sessile drop method using a contact angle goniometer. The data shown are an average of three different measurements.

\section{RESULTS AND DISCUSSION}

\section{Preparation of PE/PDMS polymer composite in $\mathrm{scCO}_{2}$}

Figure 3 shows the effect of polymerization time on the percentage of mass gain of PDMS into PE substrate and the pressure after polymerization. As expected, it is obviously observed that the mass gain increases by successive additions until $3 \mathrm{~h}$, following which it remains almost constant. Under this condition $\left(P<10 \mathrm{MPa}, T=80^{\circ} \mathrm{C}\right)$, PDMS does not dissolve in $\mathrm{scCO}_{2} \cdot{ }^{18,19}$ When PDMS was generated on the exterior of the PE substrate, the pressure increased such that the volume of the gas phase in the vessel decreased. In the primary stage of the polymerization process (polymerization time $<3 \mathrm{~h}$ ), PDMS was polymerized both in the interior and exterior of the PE substrate. In the secondary stage (polymerization time $>3 \mathrm{~h}$ ), PDMS was polymerized only in the exterior of the PE substrate. The formation mechanism of the PE/PDMS polymer composite is as follows (Figure 2): the monomer is impregnated into the $\mathrm{PE}$ substrate by $\mathrm{sCCO}_{2}$ and polymerized in situ because PDMS does not dissolve in $\mathrm{scCO}_{2}$. To further increase the mass gain, the amount of monomer inside the PE substrate should be increased. For example, changing the initial pressure, side chain of D4 and soaking time may be considered. It is considered that increasing the initial pressure and changing the side chain of D4 will increase the solubility of the monomer in $\mathrm{scCO}_{2} \cdot{ }^{20-24}$ The amount of impregnated low-molecular-weight components also depends on the soaking time and it attains an 


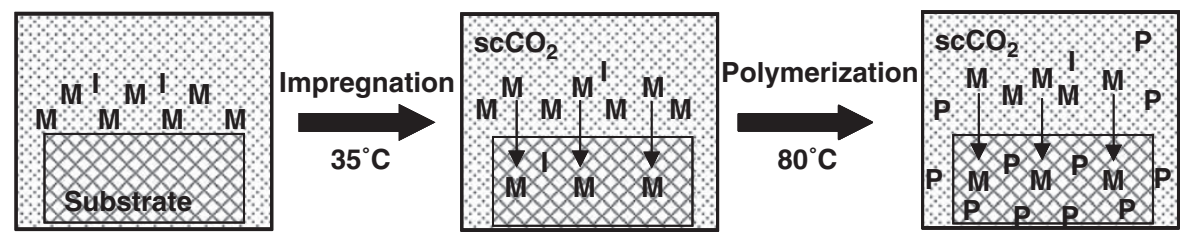

Figure 2 The formation mechanism of the PE/PDMS polymer composite. M, monomer (D4); P, polymer (PDMS); I, initiator $\left(\mathrm{H}_{2} \mathrm{SO}_{4}\right)$.

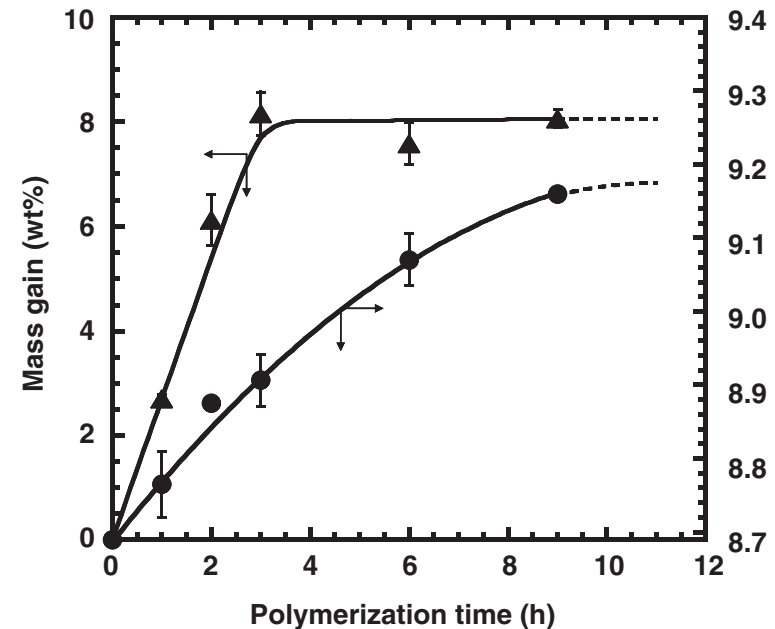

Figure 3 Effect of polymerization time on mass gain of PDMS into PE substrate and the pressure after polymerization (triangles: mass gain; circles: pressure).

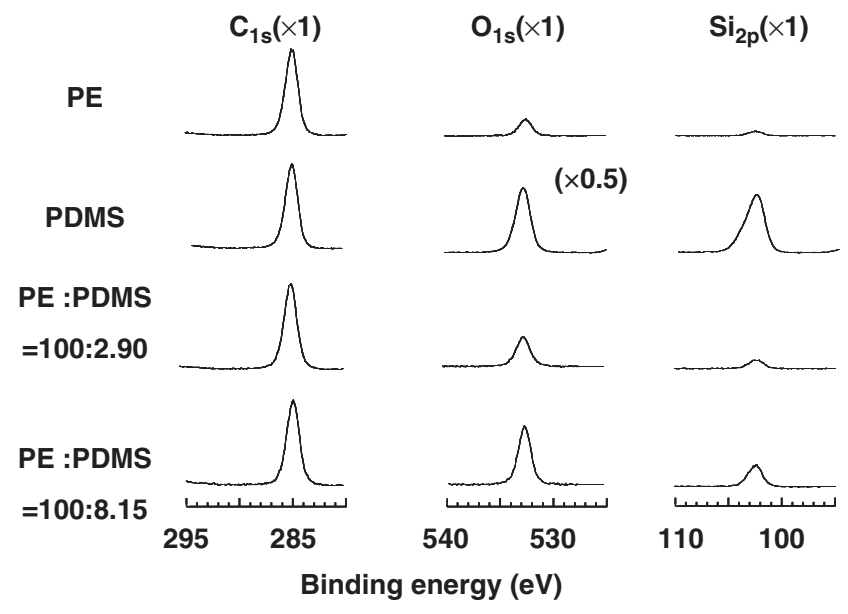

Figure 4 XPS charts of PE, PDMS and PE/PDMS polymer composites. (Takeoff angle is $90^{\circ}$.)

equilibrium value after a certain time. ${ }^{25}$ The soaking time results in equilibrium in the monomer concentration between the interior and exterior of the PE substrate. Thus, it is believed that polymerization of the monomer in the substrate can be further enhanced by changing the initial pressure, side chain of the monomer and soaking time.

Surface analysis of PE/PDMS polymer composite

Figure 4 shows the XPS diagrams of PE, PDMS and PE/PDMS polymer composites. In the case of $\mathrm{PE}$, a strong intensity is observed at $285 \mathrm{eV}$. This is attributed to the carbon atoms in the ethylene chain. In addition, two small peaks are observed at 533 and $102 \mathrm{eV}$. These peaks are attributed to the oxygen and silicon atoms, respectively, and

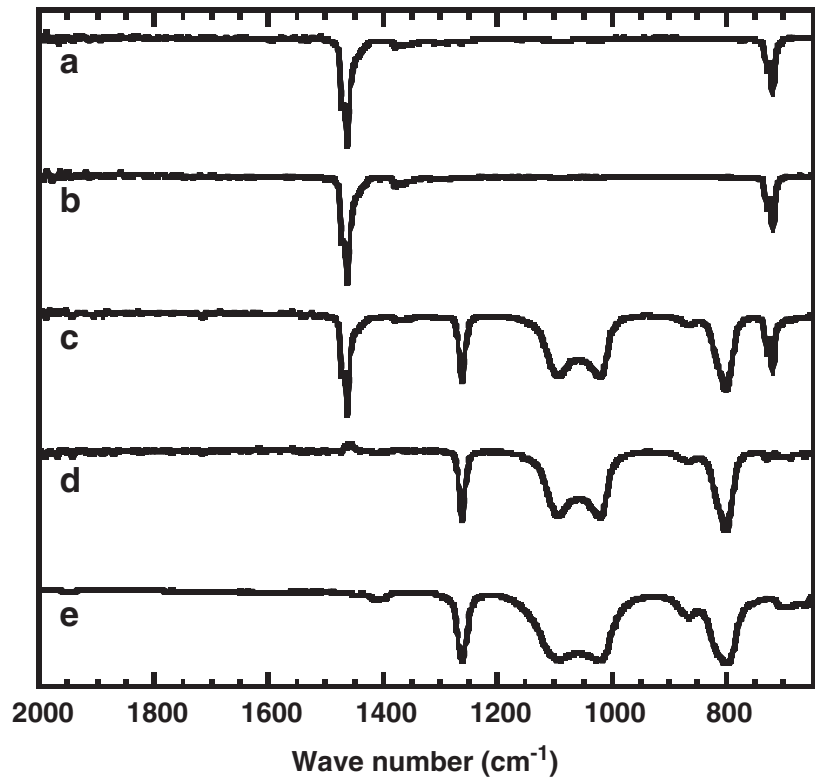

Figure 5 ATR-FTIR spectra of (a) original PE substrate, (b) PE treated with $\mathrm{ScCO}_{2}$, (c) PE/PDMS polymer composite with a mass gain of $8.15 \%$, (d) differential spectrum ((PE/PDMS polymer blend)-(PE)) and (e) PDMS.

they may arise from the oxidation or contamination of PE. In PDMS, three strong peaks are observed at 285, 533 and $102 \mathrm{eV}$. These are attributed to the constituent atoms in the PDMS chain. In the PE/ PDMS polymer composite, except for the carbon peak of PE, the strength of the oxygen and silicon peaks increases. Further, it increases with the mass gain of the PE/PDMS polymer composite (this is more evident in Figure 6). It can be concluded that PDMS prepared by cationic polymerization was generated in the vicinity of the surface.

Figure 5 shows the ATR-FTIR spectra, in which (a) shows the spectrum of the original $\mathrm{PE}$ substrate and (b) shows the spectrum of the $\mathrm{PE}$ treated with $\mathrm{scCO}_{2}$. It can be seen that they are almost identical. This implies that $\mathrm{scCO}_{2}$ does not affect the chemical structure of PE during the course of swelling. ${ }^{25}$ In the same figure, (c) shows the spectrum of the PE/PDMS polymer composite with a mass gain of $8.15 \mathrm{wt} \%$. New peaks are observed at $800,1021,1093$ and $1261 \mathrm{~cm}^{-1}$. They are attributed to PDMS. Also in Figure 5, (d) shows the differential spectrum ((PE/PDMS polymer blend)-(PE)) and (e) shows the spectrum of PDMS. As expected, the differential spectrum almost corresponds to the spectrum of PDMS. The spectra confirm that PDMS was formed within the PE substrate.

In Figure 6, (a) shows the relationship between the ratio of ATR-

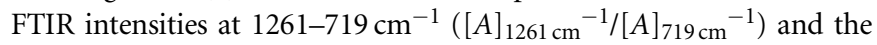
mass gain of PDMS. The ATR-FTIR absorption at $719 \mathrm{~cm}^{-1}$ $\left([A]_{719 \mathrm{~cm}^{-1}}\right)$ can be attributed to the methylene chain in the PE substrate. The new absorption at $1261 \mathrm{~cm}^{-1}\left([A]_{\left.1261 \mathrm{~cm}^{-1}\right)}\right.$ can be attributed to the $\mathrm{Si}-\mathrm{CH}_{3}$ bond in PDMS. Further, the intensity 
increased with the mass gain of PDMS. Also in Figure 6, (b) and (c) show the relationship between the ratio of the XPS atom concentration of silicon to carbon $\left(\mathrm{Si}_{2 \mathrm{p}} / \mathrm{C}_{1 \mathrm{~s}}\right)$ and the mass gain of PDMS. The takeoff angles of the photoelectron for each atom of (b) and (c) were 30 and $90^{\circ}$, respectively. In (b), the value of $\mathrm{Si}_{2 \mathrm{p}} / \mathrm{C}_{1 \mathrm{~s}}$ is almost constant. This implies that the amount of PDMS in the topmost surface is almost constant. Overall, the value of $\mathrm{Si}_{2 \mathrm{p}} / \mathrm{C}_{1 \mathrm{~s}}$ in (c) is larger than that in (b). The variation trends of curves are different in (a), (b) and (c). This can be attributed to the different measurement depths of IR and XPS (30 and $90^{\circ}$, respectively). These results imply that the PDMS near the surface could be controlled by the mass gain of PDMS, namely, the polymerization time.

SEM-EDX analysis provides further evidence that PDMS is generated in the PE substrate. The mapping micrographs detected by EDX analysis show an accumulation of silicon and carbon in the PE/PDMS

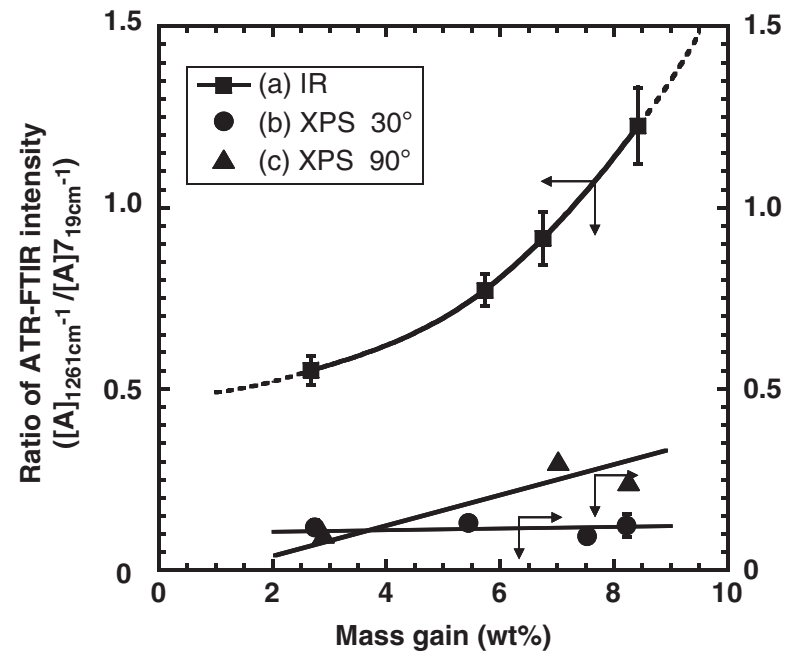

Figure 6 (a) Relationship between the ratio of ATR-FTIR intensities at 1261$719 \mathrm{~cm}^{-1}$ and the mass gain of PDMS. (b and c) Relationship between the ratio of XPS atom concentration of silicon to carbon and the mass gain of PDMS. polymer composite. The silicon concentration confirms the strong presence of PDMS. Thus, in Figure 7, in the case of small mass gain (2.86 wt\%), PDMS exists near the surface of the PE substrate. In the case of large mass gain (8.97 wt\%), PDMS exists within and near the surface of the PE substrate, and the PE/PDMS polymer composite approaches a uniform structure. This is more obvious in Figure 8. Figure 8 shows the relationship between the ratio of the EDX atom concentration of silicon to carbon $(\mathrm{Si} / \mathrm{C})$ and the distance from the polymer surface of $\mathrm{PE} / \mathrm{PDMS}$. It is evident that relative to the surface $(0-50 \mu \mathrm{m})$, the value of Si/C is very small in the $200-250 \mu \mathrm{m}$ region in the case of small mass gain $(2.75 \mathrm{wt} \%)$; however, it does not change much in the case of large mass gain $(8.87 \mathrm{wt} \%)$. This indicates that the result shown in Figure 7 is correct. Structure control in the depth direction is possible depending on the control of the mass gain, that is, the polymerization time.

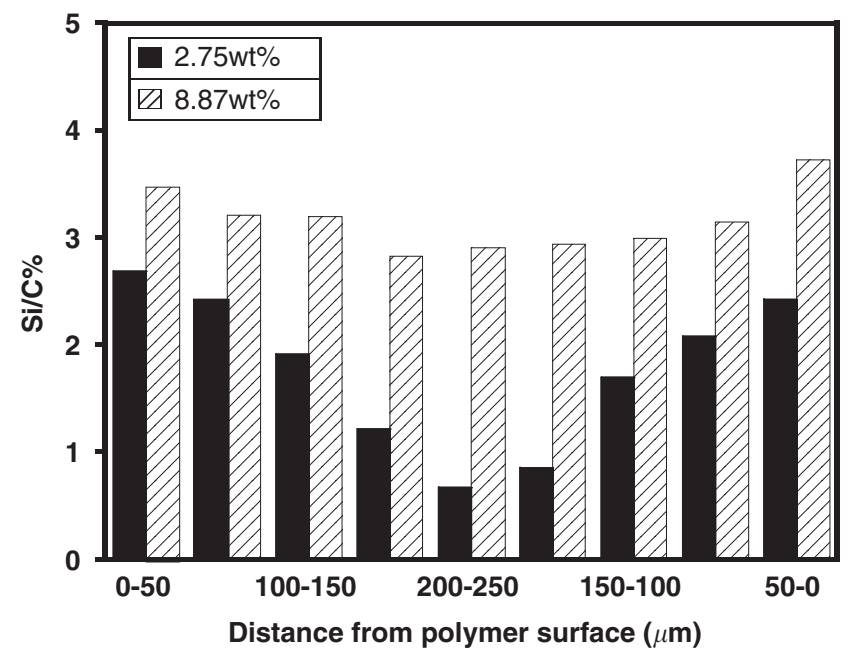

Figure $8 \mathrm{Si}$ concentration, detected by EDX analysis, in the cross-section of PE/PDMS polymer composites (mass gain: 2.75 and $8.87 \mathrm{wt} \%$ ).

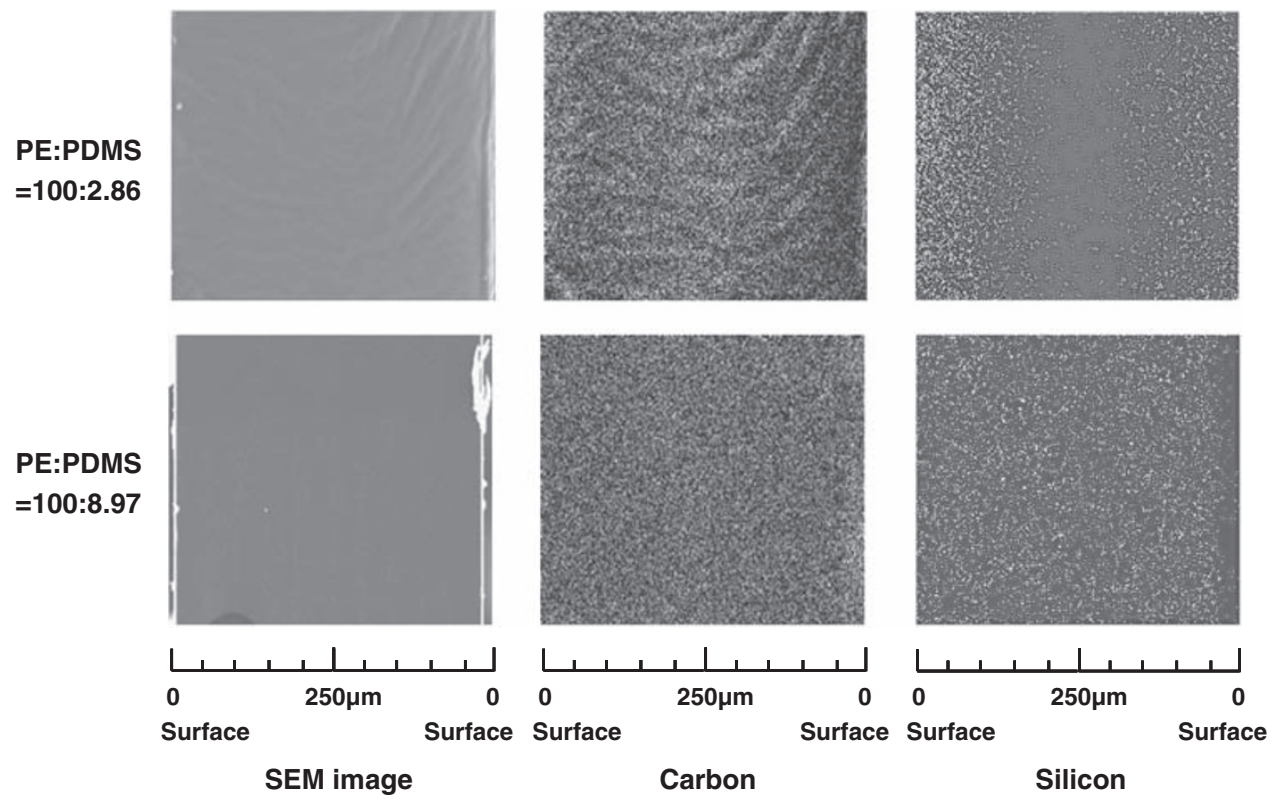

Figure 7 SEM micrographs of cross-section of the PE/PDMS composite and EDX mapping of C and Si present in the cross-section of the composite. 


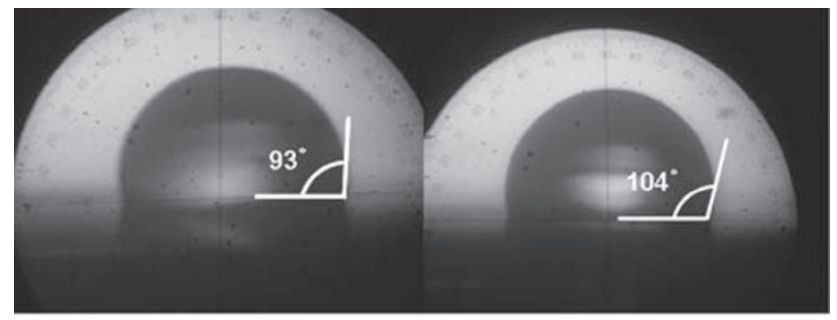

PE

PE:PDMS=100:2.58

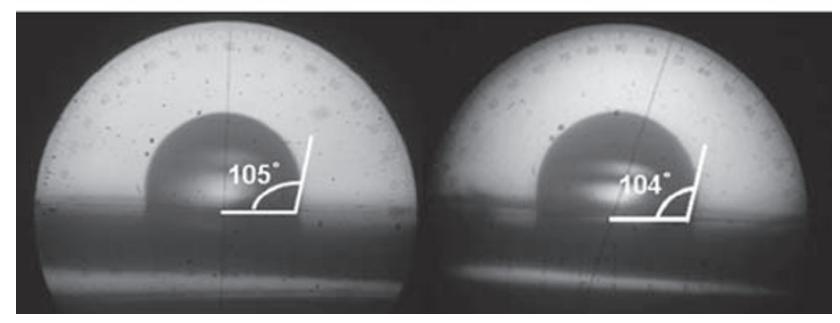

PE:PDMS=100:5.44

PE:PDMS=100:8.37

Figure 9 Pictures of static contact angle measurements of the surface of PE and PE/PDMS polymer composites.

Table 1 Results of static contact angle measurements of PE, PDMS and PE/PDMS composites

\begin{tabular}{lcccc}
\hline Sample & Run1 & Run2 & Run3 & Average \\
\hline PE & 95 & 94 & 94 & 94 \\
PDMS & - & - & - & $117^{27}$ \\
PE:PDMS $=100: 2.58$ & 104 & 102 & 105 & 104 \\
PE:PDMS $=100: 5.44$ & 105 & 105 & 105 & 105 \\
PE:PDMS $=100: 8.37$ & 104 & 101 & 106 & 105 \\
\hline
\end{tabular}

Abbreviations: PDMS, polydimethylsiloxane; PE, polyethylene.

\section{Surface properties of PE/PDMS polymer composite}

Figure 9 shows the static contact angle of all the specimens. These photos were obtained by using a normal digital camera. The contact angles can be observed intuitively from these photos. For surfaces with comparable structures, a relatively high contact angle value generally implies high hydrophobicity. In Table 1 , the value of the PE/PDMS polymer composite is larger than that of $\mathrm{PE}$, less than that of PDMS and almost constant on changing the mass gain of PDMS. This is because only the PDMS that is at a depth of $0.2-3 \mathrm{~nm}$ affects the hydrophobicity. ${ }^{26}$ These results imply that the hydrophobicity of PE has been improved. It should be noted that the hydrophobicity of PE has been improved greatly when the mass gain of PDMS generated in the surface of PE is small (2.58 wt $\%)$.

\section{CONCLUSION}

We have succeeded in obtaining a PE/PDMS polymer composite by in situ cationic polymerization using $\mathrm{scCO}_{2}$. Further, the depth to which PDMS was excited in the PE substrate was analyzed by XPS, IR and SEM-EDX, in order to control the structure of the PE/PDMS polymer composite by varying the polymerization time. The hydrophobicity of PE has been improved. Surface modification of PE could be realized. We conclude that this is a new method for modifying surface properties. In addition, the mechanical properties of the substrate material can be expected to improve.

1 Utracki, L. A. History of commercial polymer alloys and blends (from a perspective of the patent literature). Polym. Eng. Sci. 35, 2-17 (1995).

2 Akiyama, S., Inoue, T. \& Nishi, T. Polymer Blend 56-59 (CMC Publishing Co., Ltd, Japan, 1981).

3 Watkins, J. \& McCarthy, T. Polymerization in supercritical fluid-swollen polymers: a new route to polymer blends. Macromolecules 27, 4845-4847 (1994).

4 Hoshi, T., Sawaguchi, T., Konno, T., Takai, M. \& Ishihara, K. Preparation of molecular dispersed polymer blend composed of polyethylene and poly(vinyl acetate) by in situ polymerization of vinyl acetate using supercritical carbon dioxide. Polymer 48, 1573-1580 (2007).

5 Riffle, J., Yilgor, I., Banthia, A., Wilkes, G. \& McGrath, J. Synthesis and characterization of new elastomeric polysiloxane modifiers for epoxy networks. Org. Coat. Appl. Polym. Sci. Proc. 46, 397-400 (1981).

6 Yilgor, I., Steckle, W. P. Jr., Yilgor, E., Freelin, R. \& Riffle, J. Novel triblock siloxane copolymers: synthesis, characterization, and their use as surface modifying additives. J. Polym. Sci. A Polym. Chem. 27, 3673-3690 (1989).

7 Garin, S., Lecamp, L., Youssef, B. \& Bunel, C. New polysiloxanes bearing heterocyclic groups-synthesis and curability. Eur. Polym. J. 35, 473-482 (1999).

8 Hou, S., Chung, Y., Chan, C. \& Kuo, P. Function and performance of silicone copolymer. Part IV. Curing behavior and characterization of epoxy-siloxane copolymers blended with diglycidyl ether of bisphenol-A. Polymer 41, 3263-3272 (2000).

9 Qi, R., Wang, Y., Li, J., Zhao, C. \& Zhu, S. Pervaporation separation of alkane/thiophene mixtures with PDMS membrane. J. Memb. Sci. 280, 545-552 (2006).

10 Luo, C., Meng, F. \& Francis, A. Fabrication and application of silicon-reinforced PDMS masters. Microelectronics J. 37, 1036-1046 (2006).

11 Lehmann, R., Miller, J. \& Kozerski, G. Degradation of silicone polymer in a field soil under natural conditions. Chemosphere 41, 743-749 (2000).

12 Jo, B., Van, L., Linda, M., Motsegood, K. \& Beebe, D. Three-dimensional micro-channel fabrication in polydimethylsiloxane (PDMS) elastomer. J. Microelectromech. Syst. 9, 76-81 (2000).

13 Polmanteer, K., Chapman, H. \& Lutz, M. Novel wet-process silica prepared from alkyl silicates. Part III: use in silicone elastomers for optical applications. Rubber Chem. Technol. 58, 965-972 (1985).

14 Chalykh, A. \& Avdeyev, N. Influence of molecular mass of the components on the phase equilibrium of the polyethylene-polydimethylsiloxane system. Polym. Sci. USSR 27, 2769-2777 (1985).

15 Huglin, M. \& Idris, I. Miscibility of oligomeric poly(dimethylsiloxanes) with long chain unbranched alkanes-3 observations on polydispersity. Eur. Polym. J. 21, 9-13 (1985).

16 Yang, X. \& Yao, C. Synthesis and comparative properties of poly(dimethylsiloxane) grafted alkyl acrylate. J. Appl. Polym. Sci. 106, 3600-3604 (2007).

17 Zhang, J., Busby, A., Roberts, C., Chen, X., Davies, M., Tendler, S. \& Howdle, S. Preparation of a poly(methyl methacrylate)/ultrahigh molecular weight polyethylene blend using supercritical carbon dioxide and the identification of a three-phase structure: an atomic force microscopy study. Macromolecules 35, 8869-8877 (2002).

18 Bayraktar, Z. \& Erdpgan, K. Miscibility, phase separation, and volumetric properties in solutions of poly(dimethylsiloxane) in supercritical carbon dioxide. J. Appl. Polym. Sci. 75, 1397-1403 (2000).

19 Xiong, Y. \& Kiran, E. Miscibility, density and viscosity of poly(dimethylsiloxane) in supercritical carbon dioxide. Polymer 36, 4817-4826 (1995).

20 Fink, R., Hancu, D., Valentine, R. \& Beckman, E. J. Toward the development of 'CO2-philic' hydrocarbons. 1. use of side-chain functionalization to lower the miscibility pressure of polydimethylsiloxanes in $\mathrm{CO}_{2}$. J. Phys. Chem. B 103, 6441-6444 (1999).

21 Kirby, C. F. \& McHugh, M. A. Phase behavior of polymers in supercritical fluid solvents. Chem. Rev. 99, 565-602 (1999).

22 Sato, Y., Fujiwara, K., Takikawa, T., Sumarno, Takishima, S. \& Masuoka, H. Solubilities and diffusion coefficients of carbon dioxide and nitrogen in polypropylene, high-density polyethylene, and polystyrene under high pressures and temperatures. Fluid Phase Equilib. 162, 261-276 (1999)

23 Berens, L. R., Huvard, G. S., Korsmeyer, R. W. \& Kunig, F. W. Application of compressed carbon dioxide in the incorporation of additives into polymers. J. Appl. Polym. Sci. 46, 231-242 (1992).

24 Li, D., Liu, Z., Han, B., Song, L., Yang, G. \& Jiang, T. Preparation of nanometer dispersed polypropylene/polystyrene interpenetrating network using supercritical $\mathrm{CO} 2$ as a swelling agent. Polymer 43, 5363-5367 (2002).

$25 \mathrm{Li}$, D., Han, B. \& Liu, Z. Grafting of 2-hydroxyethyl methacrylate onto isotactic poly(propylene) using supercritical $\mathrm{CO}_{2}$ as a solvent and swelling agent. Macromol. Chem. Phys. 202, 2187-2194 (2001).

26 Nakabayashi, N., Ishihara, K. \& Iwasaki, Y. Biomateriaru Vol. 35 (Corona Publishing Co., Ltd, Japan, 1999).

$27 \mathrm{Seo}$, J. \& Lee, L. P. Effects on wettability by surfactant accumulation/depletion in bulk polydimethylsiloxane (PDMS). Sens. Actuators B 119, 192-198 (2006). 